\title{
Science and Society during COVID-19 Pandemic
}

\author{
Stanislav V. Ordin** \\ Ioffe Institute, RAS, St Petersburg 194021, Russian Federation \\ *Corresponding author: E-mail: stas_ordin@mail.ru
}

DOI: $10.5185 / \mathrm{amp} .2021 .010417$

\begin{abstract}
Now that the panic over the coronavirus has plagued the entire world community, it has become clear that the progress of our civilization is in question - it either zigzags or we slide back into the caves. A societal approach to a pandemic should be dealt with dynamic and complex issues via collaborative approaches. In order to develop problem-solving techniques, basic steps should be adopted through solution-oriented processes and methods.
\end{abstract}

\section{Crisis of intelligence}

In many ways, this simply demonstrates the crisis of Intelligence in society in general, and in Science, in particular. But the whole paradox is that it is precisely this "particularity" of SCIENCE in the Intelligent Society that should be the determining force, and not be trailing behind the needs of the Society; whereas now SCIENCE is in the backyards, after exchanges, casinos, strip clubs, and restaurants.

The reasons for this paradoxical phenomenon lie in the body of science itself, developing on the basis of canonized ideas built by talented scientists more than a hundred years ago. The virus of philistinism that has penetrated into science has also replaced scientific priorities in it. The priorities of the philistine are careers, money, pleasures, food, and just living. And the bourgeois priorities themselves, the only thing that crisis science could do with the help of Ai-Padov, shifted from the real world to the virtual one. But, the processes of globalization have led to the edge becoming visible; that our Earth is not so great, and its resources, including ecological ones, are not unlimited. But faced with a specific problem, both society and science are trying to solve it from a local point of view, which is always repelled from certain unshakable infinities.

Here, one of these "unshakable infinities", in the view of people, is BUSINESS and the same pandemic. They are trying to "cure" it not by fundamental science, but by means of business with more active use of administrative and bureaucratic resources. And as a result, both society and science, which have become bureaucratic over a hundred years, without seeing a common problem, poke around in the fight against a pandemic like blind kittens. Moreover, they also negate the fundamental and simple decisions and give priority to those that bring profit. Pre-crisis management brings experienced information for future responsibility. Crisis and intelligence were related to each other, where policy makers generated pragmatic solutions during pandemic like situations.

\section{Viral decontamination}

Even in the beginning of the pandemic, a method was also proposed that automatically solves the pandemic problem - viral decontamination in the "narrow throat" in the places of maximum congestion - at the entrances to the subway, to shops, at workplaces, and in public transport; virtually everywhere where people are the most likely to be in direct or close contact. And a method that takes into account not only the design of the virus, but also its dynamics - resonant IR deactivation. It would seem that the case is small. Arrange the proposed simplest IR emitters and use the time gained to improve them. But virus research continues to be purely constructive, without taking into account the "Dynamic Element of Life" simply by those modern technical methods that are available in the traditional viral representations. This, to some extent, recalls how crisis science solved the problem of NANO - it simply re-called the traditional lines of research into NANO research, since money began to be paid for the NANO prefix.

And virus decontamination is carried out in the old fashioned way - with UV and vaccines, which as a "result" gives the maximum INFECTION to DOCTORS, as it is in the hospitals that we have a "narrow throat" that cannot be canceled by any decrees on distance. Today, contamination is detrimental to finances and require cleaning and validation. Subsequent adaptation of Good Manufacturing Practices (GMPs), which avoid contaminated products through policy, is considered the best practice.

\section{Steps towards solutions}

There is a Scientific Methodology, which if not adhered to, is not just akin to the failure to comply with the "Laws" written by careerists and athletes in the Duma, but akin to a failure to observe elementary mathematics. It is basic 
and simple and should be followed Step by Step. But the Steps need not be followed like blind kittens, but according to Science. If the work of the program is interrupted, then you must not rush to immediately correct the design of the transistor. Although its design is not perfect - the Nobel laureates for the transistor did not fully understand Losev's work "Resistance Transformer". But it is precisely on these imperfect transistors that all computers are still assembled. And the first logical step is to look for a malfunction in a computer program. Also, the first step in the fight against a pandemic should begin with the search for a systemic error in the fight against it. The second step is to look for a sore spot in the devices on the computer, and to fight the virus, in those institutions that manage this fight. And it would seem the last step, but it can be said that it should be decisive - the Fundamental Solution of the Viral Problem.

Deciding priorities of problems via selecting with network academician, theorists, fundamentalist, environmentalist, social scientist working for the science and society, spreads valid solutions for the root causes and issues across an entire social network. Overall, they were able to differentiate fact and specify underlying causes with valid information for long-term alternatives. The society evaluates and monitors the scientific products and accepts mostly which brings the long-term solution.

\section{IR decontamination}

In full accordance with the adiabatic energy decomposition, the vibration frequencies of the viruses lie in the far infrared range. At the same time, resonant infrared radiation can destroy both the "structure" of the virus and disrupt the "music of Life" characteristic of it. But traditional sources of infrared radiation consume a lot of energy, most of which is spent on "spurious radiation. The problem of suppressing parasitic radiation while simultaneously drastically reducing the energy source consumed was solved in the patent cited in the link.

The use of optically transparent dielectric crystals made it possible to increase the selectivity by 7 orders of magnitude.

The simplest implementation of this patent, which can be used for viral inactivation, is shown in Fig. 1.

Instead of fused silica, which cuts off spurious radiation, with wavelengths shorter than 2 microns, it is even more efficient to use leucosapphire, which cuts off all radiation shorter than 6 microns. But leucosapphire is more expensive than quartz.

As described in an article in the scientific and educational journal NBICS in the article "Nano-virus", it is possible that infrared radiation affects the "structure" of various nano-scale objects, including nano (proto) viruses and their destruction. But most importantly, it is possible that the dynamics of their transformation into "fullfledged" viruses may be disturbed. Violation is actually the way that even primitive man used to protect himself from disease with the help of fire. Only in this case, no fire is needed, no need to burn logs in a fire and no need to spend a lot of energy.

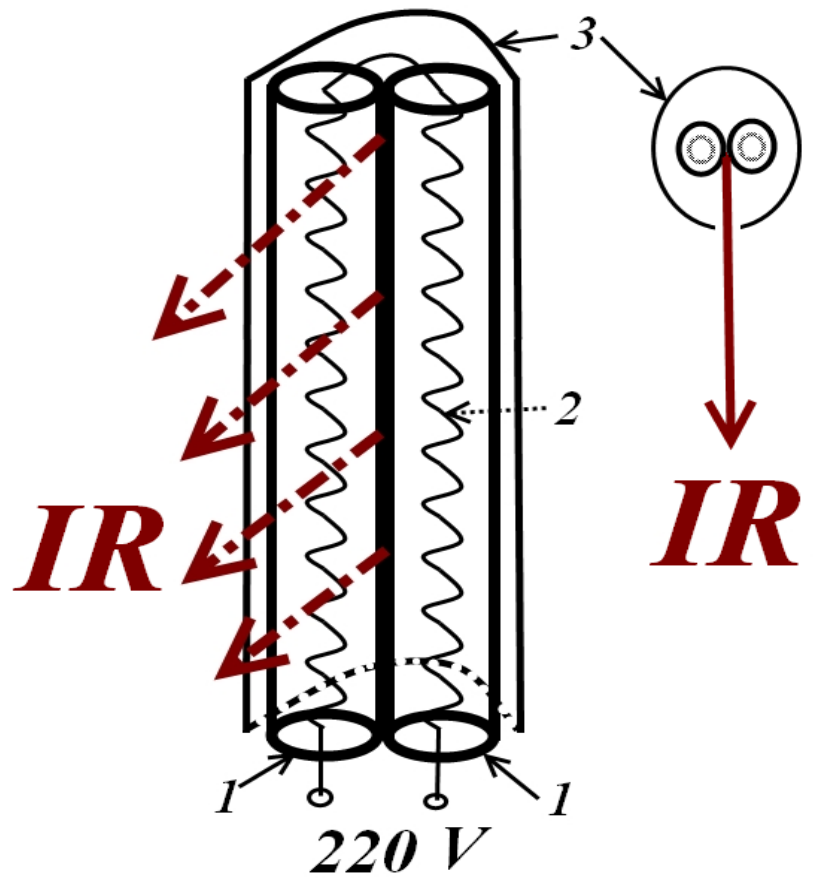

Fig. 1. Scheme of the simplest infrared disinfectant: 1 - two tubes of optical fused quartz pressed against each other, 2 - a nichrome spiral heated to a dull red light, 3 - a screen-reflector of parasitic radiation from polished aluminum.

\section{References}

1. Psychological virus:

http://www.rusnor.org/pubs/articles/18042.htm

2. NANO virus: http://www.rusnor.org/pubs/articles/18045.htm

3. Covetous virus: http://www.rusnor.org/pubs/articles/18052.htm

4. Aporia Zeno-Munchausen:

http://www.rusnor.org/network/social/user/10216/blog/3833/

5. Dynamic Element of Life:

http://www.rusnor.org/pubs/articles/15893.htm

6. Ordin S.V. "Source of Infrared Radiation", USSR Patent Inventor's Certificate No. 816250, November 21, 1980, Priority of invention - Application No. 2853190 dated December 14, 1979

7. Stanislav Ordin, "Nano-virus", NBIKS-NT, // NBICS-Science. Technologies. 2020 (4), No. 11, pp. 155-161.

Graphical abstract

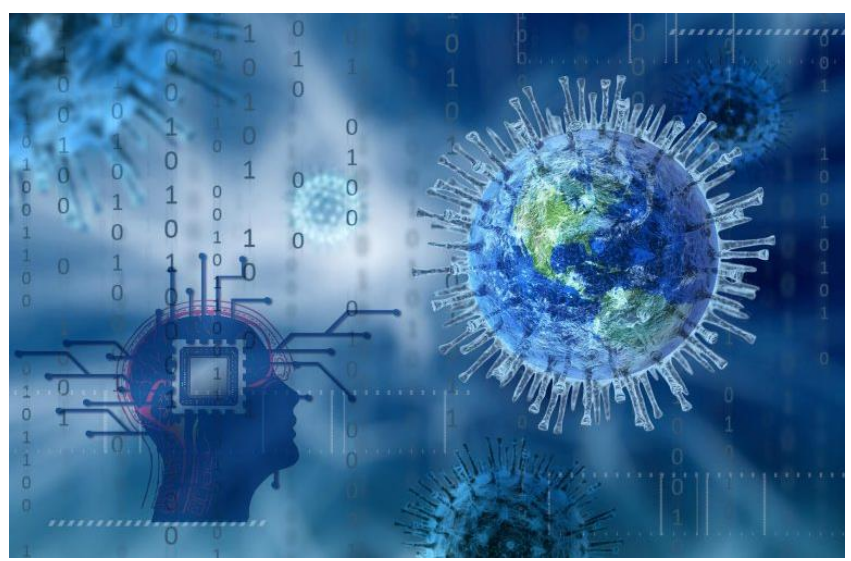

